\title{
Is there an association between bronchial asthma, food allergy/ intolerance and analgesic intolerance?
}

\section{To the Editor:}

We have read with great interest the article about food intolerance and respiratory symptoms in young adults by Woops et al. [1]. We have conducted a survey, which has not yet been published, with the aim of comparing the clinical features of patients with bronchial asthma and those with analgesic intolerance accompanying asthma. We also asked the patients whether they ever had any reactions to food, what type of reaction occurred and what food was responsible. Group I included 132 patients with bronchial asthma and analgesic intolerance and group II included 103 patients with only bronchial asthma. The mean ages were $40.7 \pm 13.0$ yrs and $43.2 \pm 14.0$ yrs for groups I and II, respectively. There was a female predominance in both of the groups $(70.5 \%$ in group I and $86.4 \%$ in group II).

Food allergy/intolerance was significantly more common in group I (22.7 and $7.8 \%$ in groups I and II, respectively, $\mathrm{p}<0.05)$. The food reported to have caused the reaction and the type of reactions are shown in table 1 . The food allergy/intolerance perception rate given in the survey by Woons et al. [1] is between our figures.

The food allergy/intolerance prevalence seems lower in Turkey than in other countries [2-4]. For example, in a survey including 4,331 Turkish university students with a mean age of $18.5 \pm 2.1 \mathrm{yrs}$, the current prevalence for food allergy/intolerance was reported as $4.5 \%$ [5]. The food

Table 1. - Food reported to have caused reactions and the type of reactions in the survey of analgesic intolerance

\begin{tabular}{lcl}
\hline & $\begin{array}{c}\text { Group I } \\
(\mathrm{n}=132)\end{array}$ & $\begin{array}{c}\text { Group II } \\
(\mathrm{n}=103)\end{array}$ \\
\hline Food allergy/intolerance & $30(22.7)$ & $8(7.8)$ \\
Tomatoes & $6(4.5)$ & $1(0.9)$ \\
Fruit & $6(4.5)$ & $1(0.9)$ \\
Other vegetables & $5(3.8)$ & $0(0)$ \\
Eggs & $4(3.0)$ & $2(2.0)$ \\
Cola drink & $3(2.3)$ & $1(0.9)$ \\
Seafood & $2(1.5)$ & $1(0.9)$ \\
Nuts & $2(1.5)$ & $1(0.9)$ \\
Chocolate & $2(1.5)$ & $0(0)$ \\
Herbs/spices & $2(1.5)$ & $2(2.0)$ \\
Garlic & $2(1.5)$ & $0(0)$ \\
Beans (dry) & $2(1.5)$ & $1(0.9)$ \\
Alcohol & $2(1.5)$ & $0(0)$ \\
Honey & $1(0.8)$ & $0(0)$ \\
Symptoms & $16(12.1)$ & $7(6.9)$ \\
Urticaria & $16(12.1)$ & $2(2.0)$ \\
Respiratory & $7(5.3)$ & $1(0.9)$ \\
Angioedema & $2(1.5)$ & $0(0)$ \\
Gastrointestinal & $1(0.8)$ & $0(0)$ \\
Nasal obstruction & & \\
\hline
\end{tabular}

Data are shown as number with percentages in parenthesis.
Table 2. - Food reported to have caused reactions in a survey of university students $(n=4,331)$

\begin{tabular}{lcc}
\hline Food allergy/intolerance & 194 & $(4.5)$ \\
\hline Fruit & 38 & $(0.9)$ \\
Eggs & 30 & $(0.7)$ \\
Chocolate & 27 & $(0.6)$ \\
Dairy products & 18 & $(0.4)$ \\
Vegetables & 17 & $(0.4)$ \\
Candies & 16 & $(0.4)$ \\
Spices/herbs & 14 & $(0.3)$ \\
Cola drink & 8 & $(0.2)$ \\
Beans (dry) & 6 & $(0.1)$ \\
Nuts & 5 & $(0.1)$ \\
Fats/oil & 5 & $(0.1)$ \\
Seafood & 3 & $(0.06)$ \\
\hline
\end{tabular}

Data are shown as numbers with percentages in parenthesis.

types reported to have caused reactions are shown in table 2. Tomatoes and fruit most commonly caused symptoms in our survey of analgesic intolerance and fruit in the survey of university students, fruit being in accordance with the study by Woons et al. [1]. Seafood allergy/ intolerance was very rare in both of our surveys compared with the survey by Woods et al. [1]. The most common symptom appearing after ingestion of the responsible food was urticaria, followed by respiratory symptoms, in our survey of analgesic intolerance, whereas the most common symptoms were gastrointestinal in origin in the study by Woods et al. [1]. These differences might be due to feeding habits and variations in the perception of various symptoms.

In the survey of university students, the prevalence of current wheezing was $4.8 \%$ and current wheezing and food allergy/intolerance were strongly associated with each other (odds ratio $=5.21 ; 95 \%$ confidence interval: $3.52-$ 7.72). Although Woods et al. [1] mentioned that the patients with current asthma did not report more perceived food allergy/intolerance, we think that asthma could be a risk factor for perceived food allergy. This discrepancy between the find-ings of our survey and the survey by Woods et al. [1] could be the result of differences in the age distribution and the selection of the two study populations. As a result, in our opinion asthma and analgesic intoler-ance may be two risk factors for food allergy/ intolerance; therefore, in future surveys on asthma and food allergy analgesic intolerance should also be taken into consideration.

G. Karakaya, A.U. Demir, A.F. Kalyoncu

Hacettepe University Hospital, Dept of Chest Diseases, Adult Allergy Unit, 06100 Syhhiye, Ankara, Turkey. Fax: 903123100809 . 


\section{References}

1. Woods RK, Abramson M, Raven JM, Bailey M, Weiner JM, Walters EH. Reported food intolerance and respiratory symptoms in young adults. Eur Respir J 1998; 11: 151-155.

2. Young E, Stoneham MD, Petruckevitch A, Barton J, Rona R. A population study of food intolerance. Lancet 1994; 343: 1127-1130.
3. Altman DR, Chiaramontte LT. Public perception of food allergy. J Allergy Clin Immunol 1996; 97: 1247-1251.

4. Jansen JJ, Kardinaal AF, Huijbers G, Vlieg-Boerstra BJ, Martens BP, Ockhuizen T. Prevalence of food allergy and intolerance in the Dutch population. J Allergy Clin Immunol 1994; 93: 446-456.

5. Kalyoncu AF, Karakoca Y, Demir AU, et al. Prevalence of asthma and allergic diseases in Turkish university students in Ankara. Allergol Immunopathol 1996; 24: $152-157$.

\section{REPLY}

\section{From the authors:}

We would like to thank G. Karakaya, A.U. Demir and A.F. Kalyoncu for their interest and comments regarding our recent paper [1]. Whilst it is reassuring that the perception of food allergy and intolerance is relatively consistent throughout many countries, it remains a major concern that such perceptions persist. This raises the question as to what strategies can be implemented on an international scale in order to decrease the gap between reported food allergies and intolerances and true reactions.

We assume that when referring to analgesic intolerance you are referring to those with aspirin and/or nonsteroidal anti-inflammatory agent intolerance. Whilst we did collect data on whether people had experienced any difficulty with breathing after taking medicines, the number of people reporting such problems was too small for any meaningful analysis to be conducted. Therefore, we cannot comment further on the finding that reported food allergy/intolerance was more common among those with both analgesic intolerance and asthma.

The reason for the lower prevalence of reported food allergy/intolerance in Turkey could be due to the population studied. The Turkish data included only university students [2], whilst out data and those of other countries [3-5] were from community samples. It is highly probable that university studies in Turkey (and elsewhere) are not representative of the population as a whole. Whilst some differences in the types of foods causing reactions are reported by G. Karakaya, we not that the data are consistent in that a wide range of foods and beverages are perceived to be associated with food allergy/intolerance. We also found an association between current wheeze and the reporting of respiratory symptoms after eating foods. However, when this was adjusted using multivariate analysis, the association was no longer significant. The numbers in the analysis were relatively small and this may be one of the reasons for not finding an association. We are currently analysing similar data from all of the countries that took part in the European Community Respiratory Survey and we will, therefore, have improved statistical power to detect clinically important associations.

In conclusion, we concur that if needed analgesic intolerance together with asthma is a significant risk factor for the reporting of food allergy/intolerance then future studies should take this into account. Furthermore, we believe that it is imperative to verify any associations that may be found between asthma and reported food allergy/ intolerance with appropriate clinical challenge studies.

R.U. Woods*+, M. Abramson*, M.J. Raven*, M. Bailey $^{*}$, M.J. Weiner ${ }^{+}$, H. Walters* ${ }^{+}$

Depts of *Respiratory Medicine, Epidemiology and Preventive Medicine and ${ }^{+}$Medicine, Monash Medical School and Alfred Hospital, Melbourne, Australia. Fax: 31 32763434.

\section{References}

1. Woods RK, Abramson M, Raven JM, Bailey M, Weiner JM, Walters EH. Reported, food intolerance and respiratory symptoms in young adults. Eur Respir J 1998; 11: 151-155.

2. Kalyoncu AF, Karakoca Y, Demir AU, et al. Prevalence of asthma and allergic diseases in Turkish university students in Ankara. Allergol Immunopathol 1996; 24: $152-157$.

3. Young E, Stoneham MD, Petruckevitch A, Barton J, Rona R. A population study of food intolerance. Lancet 1994; 343: 1127-1130.

4. Altman DR, Chiaramonte LT. Public perception of food allergy. J Allergy Clim Immunol 1996; 97: 1247-1251.

5. Jansen JJ, Kardinaal AF, Huijbers G, Vlieg-Boerstra BJ, Martens BP, Ockhuizen T. Prevalence of food allergy and intolerance in the Dutch population. J Allergy Clim Immunol 1994; 93: 446-456. 